\title{
Announcement - The Paper Award of Tribology Online -
}

The Japanese Society of Tribologists is pleased to announce that the 2008 Paper Award of Tribology Online was awarded to:

"Effect of Step Length and Walking Speed on Traction Coefficient and Slip between Shoe Sole and Walkway," by Takeshi Yamaguchi, Shintaro Hatanaka and Kazuo Hokkirigawa, Vol. 3, No. 2 (2008) 59-64.

and

"Direct Observation of Thermo-Reversible Gel-Lubricants in EHL by FT-IR Micro-Spectroscopy," by Kazutoshi Takahashi, Yuji Shitara and Shigeyuki Mori, Vol. 3, No. 2 (2008) 131-136.

The Award Medals were presented to the authors by Professor Takashi Yamamoto, the former President of the Japanese Society of Tribologists, at the Annual Meeting on 19th May, 2009.

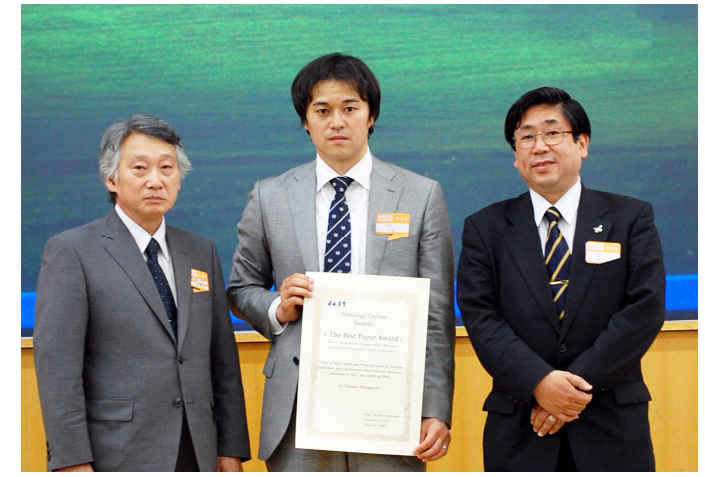

Pictured left to right: Takashi Yamamoto, Takeshi Yamaguchi, Kazuo Hokkirigawa

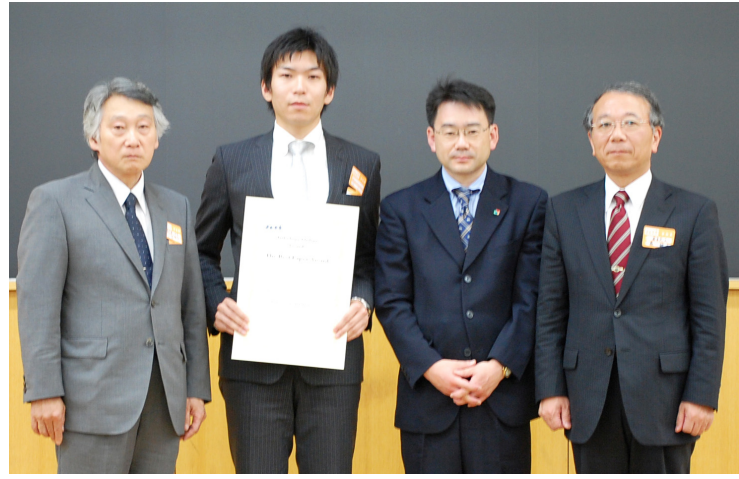

Pictured left to right: Takashi Yamamoto, Kazutoshi Takahashi, Yuji Shitara, Shigeyuki Mori

The Paper Award of Tribology Online, is a new award established this year by the Japanese Society of Tribologists. It is given annually to the author(s), either the JAST members or non-members, of the papers judged as the best paper(s) published in Tribology Online (TROL) for the previous three years. All papers that appeared in TROL for the three years are reviewed by the JAST Awards Committee.

Editor-in-Chief

Masabumi Masuko 